\title{
Etanol e biodiesel como recursos energéticos alternativos: perspectivas da América Latina e da Ásia
}

Ethanol and biofuels as alternatives energetic sources: Latin-American e Asian perspectives

GILMAR MASIERO*

HELOISA LOPES**

Rev. Bras. Polít. Int. 51 (2): 60-79 [2008]

\section{Introdução}

Em 1975 o governo brasileiro deu início ao Programa Brasileiro de Etanol, o Pró-alcool. O programa consistia em desenvolver o uso do etanol ou do etil álcool como combustível. Ele podia ser utilizado para substituir o methyl tert-butyl ether (MTBE) da gasolina ou utilizado na forma pura como combustível de veículos automotores. De 1975 a 2000, foram produzidos aproximadamente 5,6 milhóes de automóveis com motores a álcool. Além dos automóveis a álcool em menos de um quarto de século o governo aprovou a mistura de etanol na gasolina de 1,1\% a $25 \%$ em cada litro de combustível. O aspecto positivo dessa mistura foi evitar a emissão de 110 milhões de toneladas de gás carbônico na atmosfera e a importação de 550 milhões de barris de petróleo, equivalentes a US \$11,5 bilhões.

O Pró-alcool não foi a única tentativa brasileira de desenvolver combustíveis renováveis, tendo estes esforços se iniciado ainda nos anos 20 e impulsionados durante a II Guerra Mundial em função do risco de interrupção da importação de petróleo. Em 1975 o governo criou, mas não implementou o Proóleo - Plano de Produção de Óleos Vegetais para Fins Energéticos transformando-o em programa em 1983, quando dá início ao Programa Nacional de Óleos Vegetais para Produção de Energia, também chamado de Proóleo. O foco deste programa foi o desenvolvimento e a produção de biodiesel a partir de algodão, babaçu, resíduos, palma, algodão, canola, girassol, nabo forajerro, mamona, soja e gordura animal para misturá-lo ao diesel. Os esforços foram descontinuados em 1985 devido à redução dos preços do petróleo e retomados em 2003, com Programa Nacional de Produção e Uso de Biodiesel (PNPB). ${ }^{1}$

\footnotetext{
* Professor do Departamento de Administração da Universidade de Brasília-UnB (gilmarmasiero@gmail.com).

** Graduaanda em Administração pela Universidade de Brasília - UnB.

1 Programa Nacional de Produção e Uso de Biodiesel (PNPB) http://www.biodiesel.gov.br/programa.html. Disponibilidade 18/7/2007
} 
Os esforços de investigação de novas formas de energia alternativa têm sido orientados pelo aumento da demanda por biocombustíveis que ser caracteriza por: a) aumentos contínuos do preço do petróleo que hoje é a principal fonte primária de energia e devido a sua crescente utilização tem causado o encarecimento das matrizes energéticas de várias nações dependentes da commodity, desencadeando sérios desequilíbrios em suas balanças comerciais; b) benefícios que a expansão da utilização dos biocombustíveis pode trazer para o setor agrícola por meio da implantação de projetos específicos para fins energéticos com o objetivo de promover o desenvolvimento regional sustentável; e, c) redução das emissóes de gás carbônico que além do benefício em si poderá ser fonte de ganhos no mercado de carbono uma vez que a parcela de gases não emitidos por um país poderá ser comercializada na forma de créditos a outro participante interessado em não reduzir suas emissões.

Pressionados por esses fenômenos diferentes países procuram participar no novo e potencial mercado de energias alternativas ao petróleo. Nesse mercado ainda em formação, os países latino-americanos são vistos como potenciais fornecedores de etanol e biocombustíveis, enquanto as economias asiáticas, devido ao grande crescimento econômico e carência de recursos energéticos para mantê-lo, são vistas como grandes consumidores. Quais são as principais perspectivas latinas americanas e asiáticas sobre o desenvolvimento do mercado de biocombustíveis como fonte alternativa de energia?

Buscando responder a essa questão o texto segue apresentando a evolução da produção mundial de biocombustíveis, os principais produtos e produtores e alguns pontos positivos e negativos do desenvolvimento dessa nova indústria em escala global. Relata perspectivas de alguns especialistas sobre como a indústria vem se estruturando e como os países latino-americanos e asiáticos inserir-se-ão de forma competitiva nesse potencial novo mercado.

\section{A produção mundial de etanol e biodiesel}

Não existe tema mais universal que a questão dos recursos energéticos. É consenso entre estudiosos, autoridades, empresários e consumidores que o contínuo suprimento de energia pode propiciar um maior crescimento econômico e melhor qualidade de vida. Na maior parte dos trabalhos acadêmicos e relatórios governamentais a energia é claramente relacionada à segurança nacional e a estabilidade econômica global. $\mathrm{O}$ crescimento da demanda por energia tem pressionado o desenvolvimento de sistemas e tecnologias mais eficientes e a diversificação de fontes de suprimento, especialmente de energias limpas e renováveis. Às tradicionais fontes energéticas de carvão, petróleo e gás gradativamente somamse outras como a nuclear, a elétrica, a eólica e a dos biocombustíveis.

Além de melhores tecnologias e sistemas de geração energética são crescentes também as preocupações com a infra-estrutura de distribuição e regulamentação 
comercial das novas descobertas e do crescente aumento da demanda e oferta de novas soluçōes energéticas. Grande parte do aumento da demanda energética está atrelada à expansão econômica da China e da Índia. Estes dois países vêm desenvolvendo suas economias de forma mais acentuada que os demais e tornaramse grandes consumidores de energia. Seus processos de desenvolvimento econômico somam-se às pressóes para a busca de energias substitutas ao petróleo e, nesse sentido, os biocombustíveis na forma de etanol e de biodiesel vêm despertando o interesse de todos os agentes econômicos. Várias políticas governamentais, como relacionado no item seguinte, vêm incentivando sua maior presença na matriz energética de diferentes países.

No maior consumidor energético do mundo, nos Estados Unidos, por exemplo, o Presidente Bush está demandando uma redução de $20 \%$ do consumo de gasolina nos próximos 10 anos e o Senado daquele país, por sua vez, tem legislado em favor da produção de biocombustíveis, especialmente do etanol produzido a partir do milho. De acordo com o Institute for 21st Century Energy $y^{2}$ e variados artigos acadêmicos e jornalísticos, o combustível de etanol (etil álcool) resulta da fermentação e destilação de açucares derivados de várias plantas como o milho e a cana de açúcar, sendo o cultivo desta última comum na faixa tropical do mundo onde o Brasil se destaca como grande produtor. Tradicionalmente o etanol é produzido em praticamente todos os países, não como combustível, mas como o principal componente das bebidas alcoólicas.

Como combustível, é empregado na mistura com a gasolina, sendo comum adicionar E10 (10\% de etanol em 90\% de gasolina). Na sua forma pura, E100 (100\% etanol), é utilizado principalmente no Brasil de forma crescente desde os anos 70. Nos Estados Unidos, com base na cultura do milho, o estado de Iowa, secundado por Illinois, Minnesota, Nebraska e South Dakota, produz aproximadamente $75 \%$ do etanol do país. No Brasil, o fenômeno da concentração produtiva, com base na cultura da cana de açúcar, se repete sendo o estado de São Paulo o maior produtor (58\%), seguido pelos estados do Paraná, Minas Gerais, Alagoas e Pernambuco. A Índia segue sendo o maior produtor de cana de açúcar do mundo, mas sua utilização como biocombustível ainda é pequena se contrastada com a produção brasileira. O gráfico 1 ilustra o ranking de países produtores de etanol combustível no ano de 2005.

2 http://www.energyxxi.org/xxi/resources/facts_ethanol.htm. Disponibilidade em 15/8/2007. 


\section{Gráfico 1}

Principais produtores de etanol em bilhões de litros em 2005

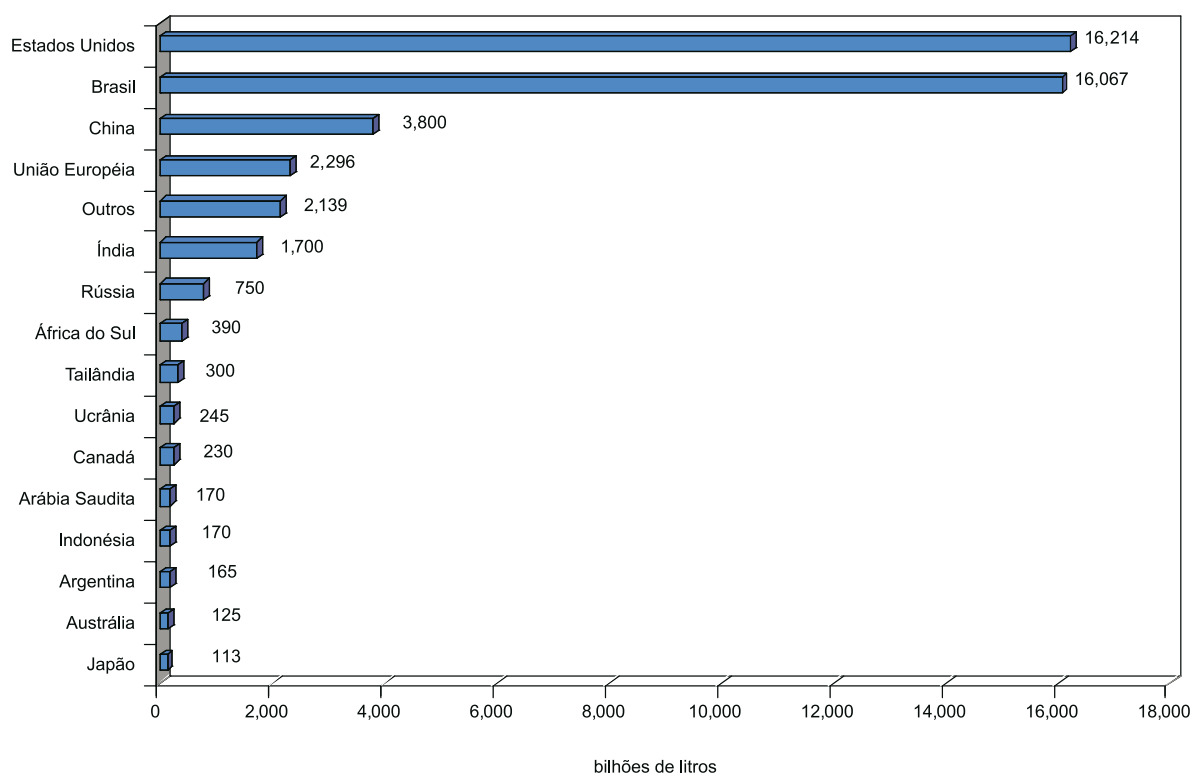

Fonte: F. O. Licht, "Ethanol: World Production, by Country," table, World Ethanol and Biofuels Report, vol. 4, no. 17 (9 May 2006), p. 395.

Nos Estados Unidos, a mistura do etanol na gasolina representou no ano de 2006 aproximadamente 3,6\% de seu consumo total, ou seja, cinco bilhões de galóes. Neste mesmo ano, segundo o Institute for 21st Century Energy existiam 120 refinarias em funcionamento e outras 80 estavam sendo construídas visando alcançar uma expansão adicional de sete bilhōes de galóes. ${ }^{3} \mathrm{O}$ Energy Policy Act de 2005 estabeleceu o requisito nacional de utilização de 7,5 bilhões de galóes de combustíveis renováveis até 2012 sendo que a maior parte deles será de etanol. Em 2007, em sua fala à nação, o Presidente Bush indicou a necessidade de o país utilizar 35 bilhôes de galôes de combustíveis renováveis até 2017. Nesse caso toda a atual produção de milho do país seria utilizada para a produção de etanol.

Ao longo de três décadas o Brasil liderou a produção de etanol combustível perdendo sua posição para os Estados Unidos após a compulsoriedade de sua utilização exigida pelo Energy Policy Act de 2005. Antes desta lei, segundo Swanson, Madden e Ghio ${ }^{4}$ o estabelecimento do American Jobs Creation Act em 2004 foi um marco na produção de biocombustíveis nos Estados Unidos. No centro dessa lei

3 ROSENTRATER, Kurt A. Economics and impacts of ethanol manufacture. BioCycle, December 2006. 4 SWANSON, Kimberly J.; MADDEN, Michael C.; GHIO, Andrew J. Biodiesel exhaust: the need for health effects research. Enviromental Health Perspectives. Volume 115. Number 4, April 2007. 
encontra-se a provisão de incentivos que permitem aos distribuidores de biodiesel receber créditos tributários que levaram segundo os autores a um crescimento de $300 \%$ da produção somente no ano de 2005. Medidas de incentivo à produção de etanol adotadas pelos Estados Unidos ou outros países têm contribuído para uma vertiginosa expansão da produção mundial de etanol como representado no gráfico 2 .

\section{Gráfico 2}

Produção mundial de etanol em milhões de litros, 1975-2005

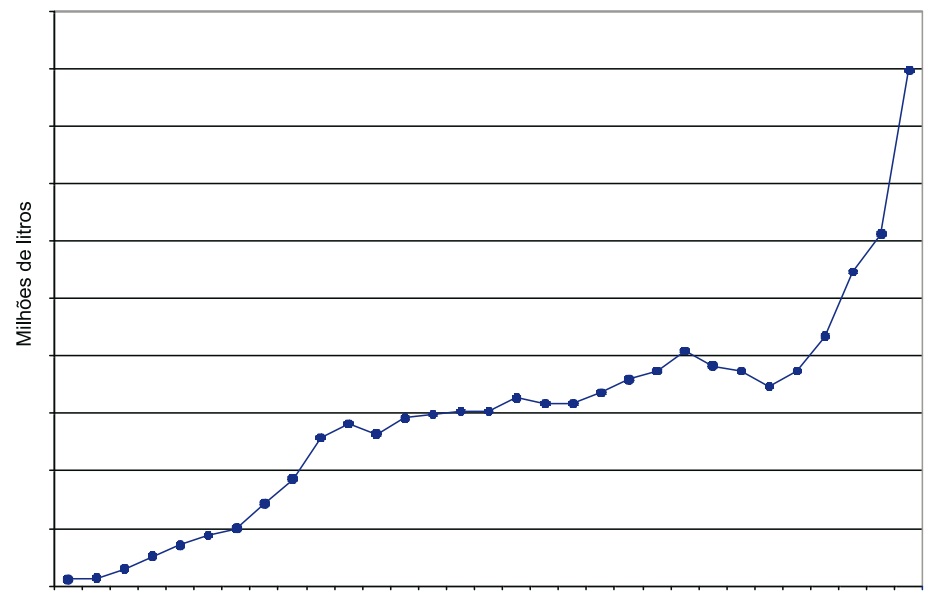

Fonte: Compilado por Earth Policy Institute a partir dos dados do F.O. Licht, citedo em Suzanne Hunt and Peter Stair, "Biofuels Hit a Gusher," Vital Signs 2006-2007 (Washington, DC: Worldwatch Institute, 2006), pp. 40-41, and from F.O. Licht, "Ethanol: World Production, by Country," table, World Ethanol and Biofuels Report, vol. 4, no. 17 (9 May 2006), p. 395.

$\mathrm{Na}$ maior parte dos paises produtores de etanol combustível e em relatórios de agências oficiais como o The Global Biofuels Outlook $2007^{5}$ os proponentes da expansão da produção argumentam que o mesmo possibilita uma maior diversidade da matriz energética e maior independência das fontes de energias fósseis. Argumentam que seu uso reduz a poluição e que propiciaria um maior desenvolvimento de regiōes agrícolas. Uma maior utilização do etanol também contribuiria para a redução das emissões de gás carbônico na atmosfera. A National Corn Growers Association, por exemplo, informa que 4,9 bilhōes de galōes de etanol combustível consumidos em 2006 reduziram 8 milhōes de toneladas de emissōes de $\mathrm{CO}_{2}$, o que equivaleria a remover 1,2 milhōes de veículos das estradas.

Parte considerável da literatura sobre a expansão da produção de biocombus-

5 The Global Biofuels Outlook 2007. A blueprint for Green Energy in the Americas: Strategic Analysis of Opportunities for Brazil and the hemisphere. Prepared by Garten Rothkopf for the Inter-American Development Bank. 2007. 
tíveis ressalta, porém, vários aspectos negativos da mesma. O principal deles, como salienta os professores Runge e Senauer ${ }^{6}$ em artigo recente na Foreign Affairs, é o aumento dos preços dos produtos agrícolas e o seu impacto na alimentação da parcela mais pobre da população mundial. Nos Estados Unidos, por exemplo, o preço do milho no mercado de futuros cresceu de US\$2,50 ao bushel (um bushel corresponde a 2,2 sacas de 60 quilos) em setembro de 2006 para US \$ 4,16 por bushel em janeiro de 2007. O aumento nos preços dos produtos utilizados para a produção de etanol e biodiesel provoca um deslocamento da produção agrícola de outras culturas ou mesmo de suas funções originais ocasionando elevações de preços em outros produtos e indiretamente na produção animal.

Vários estudiosos e organizações não governamentais chamam a atenção para a limitada poupança de energia e de ganhos ambientais com a expansão da produção dos biocombustíveis. Segundo eles, o impacto pode até mesmo ser negativo, pois o cultivo em larga escala de vegetais para a produção de bioenergia requer grandes quantidades de água, fertilizantes e pesticidas. Se o manejo não for adequado o plantio extensivo e intensivo pode também degradar o solo e destruir ecossistemas. Outro aspecto negativo e que gradativamente vem sendo superado pelos avanços tecnológicos é a baixa taxa de retorno energético de algumas plantas utilizadas no processo de produção de etanol e biodiesel. Enquanto o etanol de cana-de-açúcar possui uma taxa de aproximadamente 8 e o biodiesel de óleo de dendê aproximadamente 9, o etanol de milho apresenta uma taxa de retorno energética de 1,5 e 3 para o biodiesel de soja.

Nos cálculos das taxas de retorno energético dos biocombustíveis o rendimento das diferentes culturas por hectare de terra cultivada é uma das variáveis mais importantes. Fulton et al, ${ }^{7}$ contrastaram o rendimento das culturas mais utilizadas para a produção de etanol com as utilizadas para o processamento de biodiesel como apresentado no gráfico 3. Dado o baixo rendimento por hectare de grande parte das culturas utilizadas na produção de biocombustíveis a necessidade de significativas extensões de terra agricultáveis é indispensável para seu cultivo. Desmatamentos, queimadas e utilização dos solos com base em critérios econômicos de curto prazo visando a um rápido aumento da produção dos biocombustíveis têm se apresentado urgentes desafios a serem controlados e superados.

6 RUNGE. C. Ford; SENAUER, Benjamin. How Biofuels Could Starve the Poor. Foreign Affairs, May/ June 2007.

7 FULTON, et al., Biofuels for Transport: An International Perspective. Paris: International Energy Agency. 2004. 


\section{Gráfico 3}

Produção por hectare de plantas utilizadas na produção de biocombustíveis
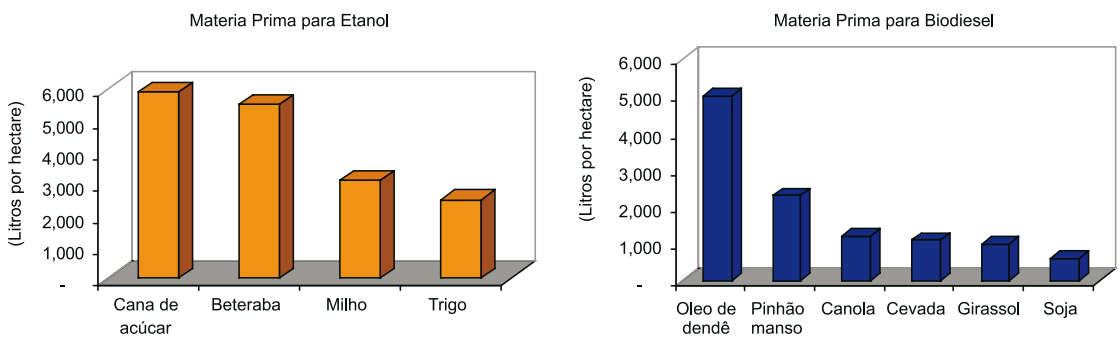

Fonte: International Energy Agency, Biofuels for Transport: An International Perspective (OECD, 2004).

Outro problema relacionado à produção em larga escala de biocombustíveis está associado a necessidade de expansão da infra-estrutura de produção e de distribuição. Em várias regiōes o etanol e o biodiesel continuam sendo mais caros que os combustíveis fósseis sendo subsidiados direta ou indiretamente para viabilizar sua produção. Nos Estados Unidos, por exemplo, os produtores de etanol recebem subsídios diretos de US\$ 0,51 por galão e na União Européia, segundo Jank et al. os subsídios indiretos, em 2004, foram da ordem de US\$ 1,6 bilhão para os produtores de azeites e US\$ 15 bilhōes para os produtores de cereais. ${ }^{8}$ A Figura 1 sintetiza a diversidade de subsídios destinados à cadeia produtiva dos biocombustíveis.

\section{Figura 1}

Subsídios à cadeia produtiva dos biodieseis

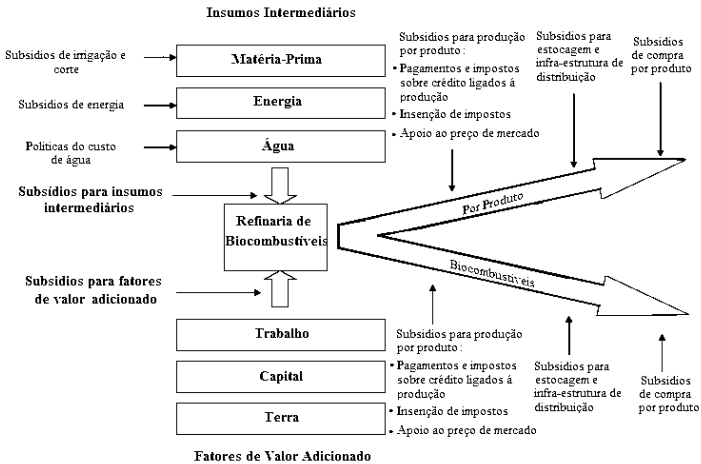

Fonte: Figura reproduzida de STEENBLIK, R.; SIMÓN J.; Biofuels - At What Cost? Government Support for Ethanol and Biodiesel in Switzerland, Global Subsidies Initiative of the International Institute for Sustainable Development, Geneva, 2007.

8 JANK, Marcos et al. EU and U.S. Policies on Biofuels: Potential Impacts on Developing Countries, German Marshall Fund of the United States, Washington, D.C. 2007. 
Enquanto já existem centenas de usinas produtoras de etanol combustível principalmente nos Estados Unidos e no Brasil ainda são poucas as que se dedicam à produção de biodiesel. $\mathrm{O}$ crescimento do número de usinas produtoras de biodiesel vem expandindo a taxas superiores as produtoras de etanol. Nos primeiros cinco anos deste século o número de usinas produtoras de etanol praticamente dobrou enquanto as produtoras de biodiesel, partindo de uma base menor, quadruplicaram. A produção mundial de biodiesel ainda é embrionária se comparada com a produção de etanol. O Gráfico 4 demonstra o crescimento da produção de biodiesel de 1991 a 2005.

\section{Gráfico 4}

Produção mundial de biodiesel em milhões de litros de 1991-2005

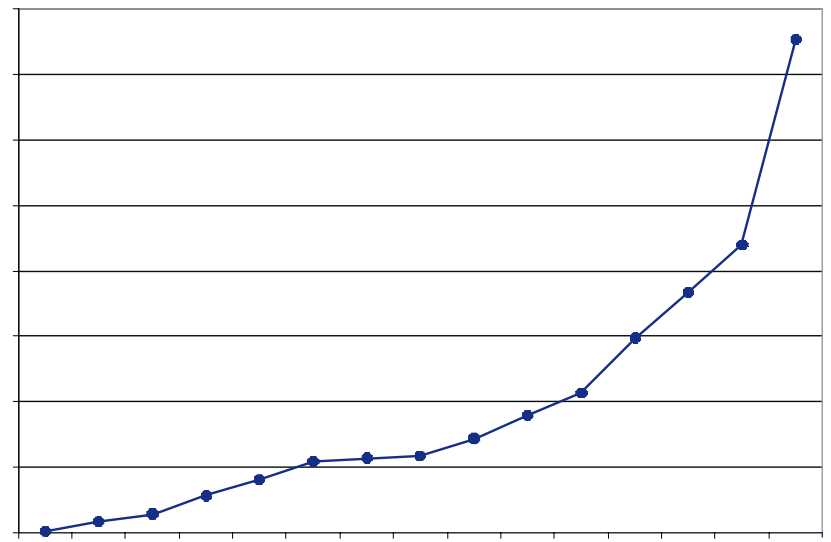

Fonte: Compilado por Earth Policy Institute a partir dos dados do F.O. Licht, citados em Suzanne Hunt e Peter Stair, "Biofuels Hit a Gusher," Vital Signs 2006-2007 (Washington, DC: Worldwatch Institute, 2006), pp. 40-41, e da tabela do F.O. Licht, "World - Biodiesel Production (tonnes)," World Ethanol and Biofuels Report, vol. 4, no. 16 (26 april 2006), p. 365.

Ao longo de todo o século XX, o biodiesel sempre foi um potencial combustível e utilizado em pequena escala em várias experiências desenvolvidas em diferentes ocasiōes históricas. Quando da invenção dos motores á combustão no início do século passado Rudolph Diesel já o empregava em seus experimentos e considerava viável sua utilização. Durante a Segunda Guerra Mundial e mais tarde quando das duas grandes crises do petróleo de 1973 e 1976 a utilização de biocombustíveis para transporte proliferaram e desde então o interesse em seu aproveitamento como substituto dos combustíveis fósseis tem sido crescente.

O biodiesel pode ser produzido a partir de óleos vegetais ou animais. Entre os vegetais mais comuns utilizados na produção desta renovável fonte energética encontra-se a canola, o girassol, a soja e o óleo de palma produzido em grande escala na Malásia e na Indonésia. A Alemanha em 2005 processou 1.920 milhões de litros é o maior produtor mundial de biodiesel extraído basicamente da 
beterraba. Naquele ano, a França, o segundo maior produtor, beneficiou 511 milhōes e os Estados Unidos, 290 milhōes. Embora a Malásia e a Indonésia sejam os maiores produtores do insumo de maior rendimento na produção de biodiesel seu processamento nesses dois paises ainda encontra-se em fase experimental. Em 2005, Estados Unidos, União Européia e o Brasil foram responsáveis por $95 \%$ da produção mundial de biocombustíveis sendo na seqüência o Canadá, a China e a Índia os maiores produtores.

\section{Algumas visões sobre a formação de um mercado global de biocombustíveis}

Qual o sistema de regulação do emergente mercado mundial de etanol e biocombustíveis é a principal pergunta de autoridades publicas e privadas em todos os continentes. Para Guilherme Leite da Silva Dias é necessário "um novo aparato regulatório para o biodiesel do futuro". ${ }^{10}$ Segundo ele, todos os mercados são direta ou indiretamente regulados pelo Estado. Na Europa e no Japão, o preço do petróleo foi mantido alto para preservar a malha ferroviária instalada. Nos Estados Unidos, os oligopólios das sete grandes empresas exploradoras do petróleo mantiveram os preços dos derivados baixos e as ferrovias perderam espaço para os transportes rodoviários.

Para este pesquisador no Brasil, o preço do petróleo foi mantido alto o suficiente para dar lucro excepcional a Petrobrás, que investiu pesadamente na busca da auto-suficiência. No Brasil, o álcool é barato porque, no distribuidor final, o preço da gasolina é onerado por quase $50 \%$ de impostos. Sem esta tarifa o álcool brasileiro não seria competitivo e como na esmagadora maioria dos outros países onde é produzido necessitaria de subsídios. Nos Estados Unidos o preço da gasolina é baixo. O álcool brasileiro não consegue entrar, nem conseguirá ser exportado para aquele país, porque àquele país possui visão estratégica acerca de sua autonomia e possibilidades energéticas. Mesmo que as atuais elevadas taxas sobre o etanol e os demais biocombustíveis importados para suprir seu mercado fossem diminuídas, o álcool brasileiro seria competitivo com o álcool americano devido a sua onerosa produção a partir da cultura do milho, mas não competiria com a gasolina que possui um nível de tributação comparativamente baixo.

Além do grande mercado consumidor de energia dos Estados Unidos, por pressões ambientais haverá substituição do MTBE por etanol em níveis em torno de $7 \%$ a $10 \%$. Porém, para que os biocombustíveis causem uma grande revolução, segundo Guilherme Dias, os países produtores desta nova fonte de energia renovável não devem produzi-la para misturá-la com as energias fósseis,

9 IEA. World Energy Outlook 2006, Chapter 14, The Outlook for Biofuels, OECD Publications, Paris. 2006. 10 DIAS, Guilherme Leite da Silva. Um desafio novo: o biodiesel. Estudos Avançados. Vol. 21, n. 59. São Paulo. Jan./abr. 2007. 
mas sim deveriam substituí-las. Para Dias, a melhor estratégia para o Brasil é desenvolver um mercado para os carros flex; isto é, vender carro e combustível para países pequenos criando pouco a pouco demanda para sua produção de tecnologia e combustíveis renováveis. Para os países de maior porte, essa estratégia não funcionaria, pois os Estados Unidos não irão abrir seu mercado. O Japão e União Européia também não abrirão, a menos que tenham fortes garantias de fornecimento em grande escala.

Os mercados agrícolas, principalmente dos países já desenvolvidos, têm sido os mais protegidos por barreiras tarifárias e alfandegárias. Os impasses nas atuais negociaçōes da Rodada de Doha têm se caracterizado pelas resistências dos países centrais em liberalizar seus mercados agrícolas. Suani Teixeira Coelho, baseado na experiência brasileira de desenvolvimento da produção de etanol discute suas vantagens e demanda a abertura dos mercados para o etanol brasileiro. Segundo ele, os subsídios aos combustíveis fósseis, os subsídios agrícolas e outras externalidades encobrem o foco central da discussão sobre os biocombustíveis, que é a "rápida melhoria da curva de aprendizagem por meio do comércio internacional liberalizado e da exploração total do potencial produtivo de biocombustíveis nos países em desenvolvimento. ${ }^{11}$

Apesar das resistências na liberalização do comércio internacional, dos problemas técnicos de classificação dos biocombustíveis como sendo um produto agrícola ou uma commodity energética como desde 2006 o governo brasileiro vem demandando, não existe certeza de que os mercados americano, europeu e japonês permanecerão sempre fechados para os biocombustíveis brasileiros. Segundo Marcos Jank, ${ }^{12}$ aos lobbies protecionistas da agricultura, se contrapõem lobbies igualmente poderosos, que não querem se sujeitar ao preço interno elevado do milho nos EUA e do óleo de colza/canola na União Européia. Para ele, há enorme espaço para o Brasil aumentar a sua presença nos grandes países consumidores de energias fósseis, cujo mercado potencial para combustíveis renováveis é enorme.

Qualquer pequena abertura comercial nos mercados centrais pode representar um aumento expressivo da demanda por biocombustíveis uma vez que toda a atual produção brasileira de álcool representa um volume equivalente a apenas $2 \%$ de substituição de gasolina nos Estados Unidos. Além desse aspecto, Jank, salienta que a imagem do Brasil está associada à sustentabilidade econômica, social e ambiental do setor de renováveis. Se o Brasil não for ecologicamente correto, pode enfrentar barreiras nos grandes mercados. Isso aponta para a necessidade de mecanização da colheita da cana de açúcar e para a intensificação do uso da terra pela pecuária, com crescimento vertical (e não horizontal) da produção.

11 COELHO, Sauani Teixeira. Biofuels - Advantages and trade barriers. UNCTAD/DITC/TED/2005/1. February 2005.

12 Ver vários artigos sobre o assunto disponíveis no site do Instituto de Estudos do Comércio e Negociações Internacionais: http://www.iconebrasil.org.br/pt/default.asp com destaque para a entrevista publicada no diário O Estado de São Paulo em 8 de julho de 2007. 
A contrapartida de curto prazo é que a colheita manual da cana de açúcar emprega hoje 250 mil trabalhadores, que podem ficar sem o emprego.

Ao problema do desemprego rural soma-se o temor da cana utilizada para a produção de etanol invadir áreas de produção de grãos que compõem a dieta das populações mais pobres do planeta. Jank, explica que é errado temer a monocultura de cana de açúcar. Dados censitários mostram justamente o contrário: uma diversificação do uso da terra graças ao incremento tecnológico nos últimos sessenta anos. Para ele também é falso o dilema alimentos versus energia uma vez que o Brasil poderia suprir toda a demanda de etanol dos Estados Unidos, de 38,6 milhôes de $\mathrm{m}^{3}$ e da UE, mais 11,4 milhões $\mathrm{de}^{3}$, em 2010, com apenas 22 milhões de hectares de cultivo da cana de açúcar. O país utilizaria somente 6,5\% da sua área agrícola ou $11 \%$ da área disponível em pastagens. Ele acredita que se as mais eficientes plantas brasileiras para produção de etanol tivessem espaço no mercado mundial, a discussão seria "alimento + combustíveis" além de se discutir o enorme potencial da bioeletricidade de origem vegetal e as certificações que atestem a sua sustentabilidade.

Essas preocupações também são consideradas por Homem de Melo, ao evidenciar que a demanda mundial por biocombustíveis exerce forte pressão nos preços dos produtos agrícolas destinados a sua produção. Para ele o ano de 2007 marca a transição de um período de crise (2005 e 2006) para um de crescimento na agricultura brasileira devido à nova demanda de fontes de bioenergia que até então não existia. ${ }^{13}$ Suas projeções mostram que nunca houve na história da agricultura brasileira época como a atual onde a produção de grãos é maior em uma menor área cultivada evidenciando claros aumentos de produtividade. Ressalta, porém, com base em dados do International Food Policy Research Institute (Ifpri) que os preços de alguns produtos que compõe a dieta alimentar das populações mais pobres estão duplicando seus preços em apenas 3 anos como evidenciado na tabela 1 .

\section{Tabela 1}

Projeções de preços em US \$ por tonelada de alguns produtos agrícolas

\begin{tabular}{lrc}
\hline Produtos & 2005 & 2008 \\
\hline Soja & 223 & 331 \\
Óleo de soja & 496 & 831 \\
Milho & 82 & 147 \\
Trigo & 117 & 235 \\
Algodão & 1.106 & 1.454 \\
\hline
\end{tabular}

13 Palestra realizada no seminário Quintas do Futuro na Universidade de Brasília em 17 de agosto de 2007. Os autores deste artigo agradecem a cessão das "notas de aulas" utilizadas por Homem de Melo em sua exposição. 
O aumento da produtividade agrícola é promissor para os agricultores e consumidores, mas o mesmo não é verdade quando os preços sobem de forma acelerada. Segundo Homem de Melo, os mais pobres gastam de $50 \%$ a $80 \%$ de sua renda na compra de alimentos e o consumo calórico cai $0,5 \%$ a cada aumento de $1 \%$ no preço. Ele indica ainda que o aumento de pessoas em situação de insegurança alimentar no Brasil pode subir em 16 milhões de habitantes para cada $1 \%$ de elevação nos preços da cesta básica. E, dando eco às apreensões expressas no artigo de Runge e Senauer, anteriormente mencionados, aponta para o fato de se essa alta for contínua, em 2025 o mundo poderá ter 1,2 bilhōes de pessoas em estado de fome crônica: 600 milhōes a mais do que é previsto atualmente. Potenciais ganhos de produtividade e aumentos de preços seguiram balizando o debate sobre "alimentos versus combustíveis" ou "alimentos mais combustíveis" no contexto mundial, asiático e latino-americano.

\section{Perspectivas latino-americanas sobre biocombustíveis}

A maior parte dos governos latino-americanos está buscando criar infraestrutura regulatória e financeira para a emergente indústria de biocombustíveis. $\mathrm{O}$ Brasil, devido ao seu pioneirismo no setor, tem firmado parcerias de transferência de tecnologia e cooperação na produção e comercialização de biocombustíveis com vários desses paises. Além do Brasil, a Colômbia se destaca no desenvolvimento de biocombustíveis. A esperança de poder diversificar o consumo de energia e de produção agrária, de criar empregos no campo e de substituir as plantações de coca por cultivos destinados à produção de biocombustíveis tem impulsionado o país a investir nesse setor. ${ }^{14}$

As expectativas de expansão da produção bioenergética é grande também na Argentina que por possuir um sofisticado agribusiness e ser pesadamente dependente de combustíveis fósseis está procurando maneiras de diversificar sua matriz energética. Tanto o setor privado, quanto o público têm investido bastante em pesquisas para criação de tecnologias e na formação de um mercado interno com incentivos de produção e garantia da demanda através do uso de combustíveis mistos. ${ }^{15}$

A total dependência externa do Paraguai por petróleo e sua economia predominantemente agrária fazem desse país um forte candidato a desenvolver uma indústria de biocombustíveis voltada principalmente para suprir demandas internas. A mistura de $24 \%$ de etanol na gasolina é compulsória e 15 novos projetos vem sendo desenvolvidos pelo governo com alguns deles relacionados

14 Quando não especificado a sistematização deste item foi realizada a partir do relatório de dados e informaçôes publicadas no The Global Biofuels Outlook 2007.

15 ASAL, Shafik; MARCUS, Remi. An analysis of the obstacles to the development of a sustainable biodiesel industry in Argentina. Université Paris-Dauphine. Buenos Aires, 2005. Ver também, Rabinovich, Gerardo http://www.mercosurabc.com.ar/nota.asp?IdNota=1250\&IdSeccion $=7$ 
à utilização de sebo animal para a produção de biodiesel. No Paraguai existe grande potencial de expansão do cultivo de insumos bioenergéticos por meio da utilização de terras subutilizadas, tornando desnecessário o desvio de terras usadas para produzir alimentos. ${ }^{16}$

Apesar do interesse de iniciar a exploração do mercado chileno de biocombustíveis por empresas chilenas ou mesmo pela brasileira Petrobras o país ainda não produz biodiesel ou etanol. O governo aprovou recentemente a Lei dos Renováveis, que será responsável pela regulação do setor, mas que requer uma maior elaboração antes que possa se transformar num eficaz instrumento de orientação dos agentes econômicos para o desenvolvimento da indústria. No longo prazo, os avanços na pesquisa para desenvolver biocombustíveis a partir de celulose poderão trazer uma grande oportunidade para o país devido ao fato do Chile ser um grande exportador de madeira.

A inexistência de produção bioenergética ocorre também no Equador. A ausência de uma política energética integrada, os contínuos subsídios do petróleo e seus derivados, a escassez de pesquisas na área e a pequena extensão das plantações de cana-de-açúcar são importantes fatores que impedem o Equador de desenvolver sua indústria de biocombustíveis. $\mathrm{O}$ setor privado, apesar de possuir interesse em investir no setor, está aguardando do governo uma postura mais pró-ativa na elaboração de uma estrutura legal que suporte o setor e a expansão de terras agriculturáveis.

No contexto sul-americano, a Venezuela que é um grande produtor de petróleo também possui potencial para ser um significativo produtor de biocombustíveis graças ao seu clima, tamanho, topografia e quantidade de terras cultiváveis. No entanto como ainda não há uma política oficial do governo para o setor e a indústria de açúcar não possui estrutura suficiente para abastecer os dois mercados, alimentício e energético, o país parece permanecer como importador de etanol por mais alguns anos. As enormes reservas de petróleo e o atual elevado preço da commodity faz com que a Venezuela careça de incentivos para a diversificação de energia. O mesmo fenômeno parece se repetir na Bolívia que tem na exportação de seu gás natural para a Argentina e o Brasil uma de suas maiores fontes de renda.

A política energética uruguaia é altamente integrada com a de outros países membros do Mercosul apresentando um cenário favorável ao desenvolvimento de biocombustíveis com um sistema legal forte e mercados financeiros abertos a novos investimentos. O governo fez vários progressos em promover a indústria, inclusive o estabelecimento da Comissão Nacional de Biocombustíveis e do Programa Nacional de Bioetanol (Pronabio-E). A capacidade da agricultura uruguaia e a necessidade do país de reduzir sua dependência das importações de petróleo além de gerar empregos rurais pressionam para o desenvolvimento

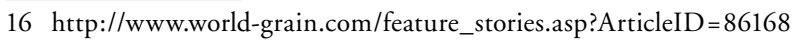


de novas indústrias e a de biocombustivel parece se adequar às características geográficas do país. ${ }^{17}$

Os elementos para o desenvolvimento sustentável dos biocombustíveis parecem estar presentes também no Peru. Uma estrutura legal básica foi construída, os índices de mistura nos combustíveis já foram instituídos, a questão ambiental tem sido considerada e o país possui uma indústria forte capaz de sustentar a produção do etanol. O Peru também assinou dois acordos de cooperação com o Brasil e negociou o acesso preferencial ao mercado dos Estados Unidos, embora este acordo ainda esteja em fase de aprovação pelo Congresso daquele país. Ainda não existem, porém, estudos suficientes sobre a viabilidade dos planos do governo de expandir a produção de cana-de-açúcar na região da Amazônia.

Na América Central países como a Costa Rica, El Salvador e Guatemala podem ser considerados os mais bem equipados para expandir a produção dos biocombustíveis. Algumas estimativas mostram que esses países possuem indicadores de produção de etanol semelhantes aos encontrados no Brasil. O clima favorável, a forte dependência de fontes estrangeiras de petróleo e a presença da cultura de cana-de-açúcar são indicadores de que Honduras, Nicarágua e Panamá também possuem grande potencial para a produção de bioenergia.

Recentemente as Nações Unidas destacaram a produção de biodiesel como uma ferramenta importante para ajudar o desenvolvimento social e econômico do Haiti, que está trabalhando com o Brasil para a transferência de tecnologia e know-how. Outros paises do Caribe, como a Jamaica, estão iniciando sua própria produção de etanol combustível e reexportando etanol brasileiro para os Estados Unidos após desidratado localmente. ${ }^{18}$ Os países do Caribe podem exportar etanol para os Estados Unidos sem nenhuma tarifa ou barreira comercial por se enquadrarem na Caribean Basin Initiative. Esta iniciativa permite que 24 países centro-americanos e caribenhos exportem a maior parte de suas mercadorias para os Estados Unidos sem o pagamento de nenhuma tarifa. ${ }^{19}$

\section{Perspectivas asiáticas de produção e comercialização de biocombustíveis}

Do ponto de vista da produção e do consumo, a China e a Índia são os principais atores asiáticos em vários setores econômicos inclusive no emergente mercado de biocombustíveis. São respectivamente o $3^{\circ}$ e $4^{\circ}$ maior produtor mundial de etanol e o $5^{\circ}$ e $6^{\circ}$ maior produtor de biodiesel. A China, na virada do século, iniciou sua produção baseada principalmente em milho, açúcar, sorgo, trigo e mandioca, como uma forma de reduzir seus elevados estoques de grãos e

17 KEN, Joseph; Uruguayan Biofuels. GAIN Report Number: UY7002. 7/20/2007.

18 http://biopact.com/2007/08/jamaica-ethanol-exports-earn-120.html

19 http://www.ustr.gov/index.html 
vem propondo seu desenvolvimento em três estágios: No atual plano qüinqüenal de desenvolvimento para o período de 2006-2010 estabeleceu como objetivo alcançar a comercialização de tecnologias relacionadas aos biocombustíveis. No plano subseqüente de 2011-2015 visualiza a produção dos mesmos em grande escala e no seu décimo terceiro plano para os anos de 2016-2020 quer substituir $15 \%$ dos combustíveis fósseis e tornar sua indústria competitiva globalmente. ${ }^{20}$

Segundo legislação de fevereiro de 2006 cinco províncias chinesas, (Jilin, Heilongjiang, Liaoning, Henan e Anhui) e outras 27 cidades devem misturar $10 \%$ de etanol na gasolina. A mistura já representa $20 \%$ do consumo de gasolina do país que utiliza o óleo diesel em sua matriz energética. Com relação à produção de biodiesel não existe nenhuma política governamental para sua produção e não existem subsídios para o setor. Iniciativas na direção de ampliar a consciência e os esforços para a utilização de energias menos poluidoras vêm sendo realizadas no âmbito da organização das olimpíadas de 2008. A China espera surpreender o mundo com seus esforços de organização da chamada Green Olympics. ${ }^{21}$ A expectativa é de rápida introdução dos biocombustíveis no país, principalmente do biodiesel.

A indústria automobilística chinesa, que é a que mais cresce no mundo deverá impulsionar a expansão de iniciativas voltadas para a produção e consumo de biocombustíveis. O mesmo processo está acontecendo com a Índia, onde a rápida expansão de sua indústria automobilística pressiona o país para reduzir seus $70 \%$ de dependência enérgica provinda do exterior. Sua vasta extensão territorial e larga tradição agrícola possibilitam imaginar que suas ainda incipientes iniciativas na área do biodiesel e etanol se expandam rapidamente. Sua produção de etanol é baseada no bagaço da cana-de-açucar e a do biodiesel no pinhão manso (jatropha), pois o país proíbe a produção de biocombustíveis derivados de culturas destinadas a alimentação humana ou animal. ${ }^{22}$

Atualmente metade dos automóveis na Índia, principalmente em dez estados, consomem $5 \%$ de etanol misturado na gasolina e o governo espera ampliar para todo o país a adição de $20 \%$ ao longo dos próximos dez anos. Seu principal problema para alcançar este objetivo encontra-se na volatilidade da produção de cana devido a fortes secas e a mesma possuir baixos teores de açucares. Outro fator restritivo é a carência de água, pois mais de 300 dos 470 distritos do país possuem seus recursos aqüíferos operando no limite. As esperanças e os desenvolvimentos tecnológicos estão sendo canalizados para o cultivo do pinhão manso que não é utilizado para alimentação e é uma planta que cresce em regiôes pouco propicias para o cultivo de qualquer outra espécie e sendo comum de regiōes secas não exige elevado consumo de água.

20 National Development and Reform Commission (NDRC). http://en.ndrc.gov.cn/. Várias notícias.

21 Ver http://en.beijing2008.cn/12/12/greenolympics.shtml.

22 SINGH, Santosh Kr. India Bio-fuels. Annual 2007. GAIN Report Number: IN7047. Date: 6/1/2007. 
No Japão e na Coréia do Sul também são grandes produtores de etanol a partir do arroz utilizado na indústria de alimentos e ainda são incipientes as iniciativas de sua utilização como combustível. Os dois países são 100\% dependentes da importação de petróleo para movimentar suas indústrias e suas frotas de veículos automotores. No Japão não existe nenhuma medida governamental obrigando a utilização dos biocombustíveis, mas o governo tem incentivado a mistura de $3 \%$ na gasolina.

$\mathrm{Na}$ Coréia do Sul, $0,5 \%$ de biodiesel proveniente do arroz ou de óleos reciclados são atualmente misturados ao diesel. O governo requeria que esta mistura fosse de 20\% (BD20) até o final de 2006, o que não ocorreu por falta de suprimentos e adaptações na indústria automotiva. Essa meta de BD20 segue sendo perseguida da mesma forma que a mistura permitida de $6,7 \%$ de etanol na gasolina, desde 2005, vem sendo buscada pelas refinarias locais. A reduzida área disponível para o cultivo de insumos para a produção de biocombustíveis tem forçado a busca do desenvolvimento de grandes plantações no exterior. Nesse sentido, o governo tem buscado estreita colaboração com o governo da Indonésia que possui tecnologia e grande produção de etanol a partir da mandioca e do óleo de dendê. ${ }^{23}$

A Indonésia, país membro da Opep - Organização dos Países Exportadores de Petróleo teve sua atenção despertada para a produção e comercialização de biocombustíveis em função do rápido declínio de suas reservas de petróleo. Seu governo lançou a Green Energy Iniative 2020 em 2005 demandando um aumento dos biocombustíveis na matriz energética do país dos atuais $0,2 \%$ para $20 \%$ em $2025 .{ }^{24} \mathrm{O}$ governo espera até 2010 substituir $2 \%$ do consumo de diesel por biodiesel de óleo de dendê ou do extraído do pinhão manso e $2 \%$ da gasolina com a mistura de $10 \%$ de etanol extraído basicamente da mandioca. Pressões ambientalistas deverão apoiar as intenções do governo, pois a Indonésia é o terceiro maior emissor de gás carbônico, devido principalmente a freqüentes queimadas de suas florestas, após os Estados Unidos e China.

É provável que parcela significativa das várias ilhas que compõem o território da Indonésia seja ocupada por grandes empresas produtoras de óleo de dendê que praticamente já esgotaram as áreas propícias para o cultivo de palmas no país vizinho a Malásia. A Malásia é o maior produtor de óleo de dendê para alimentação e desde 1982 possui um compreensivo programa de desenvolvimento de biodiesel com base nesse produto. Em 2006, estabeleceu uma Política Nacional de Biocombustíveis a partir de cinco estratégias propulsoras da nova indústria. A primeira delas é seu desenvolvimento para o transporte misturando $5 \%$ de biodiesel; a segunda, fornecer B5 para uso industrial; a terceira, desenvolver tecnologias de produção e comercialização de biocombustíveis; a quarta,

23 http://www.globe-net.ca/market_reports/index.cfm?ID_Report=1089

24 SUMARYONO, Wahono. Policy and R\&D on biofuels and biomass in Indonesia. Presentation at 2nd Biomass Biomass-Asia Workshop Bangkok, 13-15 December 2005. http://www.unit.aist.go.jp/internat/ biomassws/02workshop/reports/2005121302CR-INDONESIA.pdf 
encorajar sua produção para a exportação e a quinta, utilizar os biocombustíveis para reduzir o uso das poluidoras energias fósseis. ${ }^{25}$

Outro país asiático com potencial para ser um grande produtor de biocombustíveis é as Filipinas. Em 2005 uma lei possibilitou a mistura de etanol na gasolina e em 2006, considerou a possibilidade da mistura de biodiesel. A montadora de veículos Ford já instalou uma fábrica de motores flex power no país e de acordo com Marlon Apanada o mesmo busca se posicionar no sudeste asiático como um desenvolvedor de biomassa, distribuidor regional de veículos flex power e grande estocador de biocombustíveis proveniente de terceiros paises para serem comercializados naquele entorno geográfico. ${ }^{26}$ Nesse entorno de grande heterogeneidade de povos e diferenciados desafios desenvolvimentistas sendo enfrentados pelos principais produtores de insumos para a indústria dos biocombustíveis relacionados acima (ou por outros como a Tailândia, Vietnam, Laos, Bangladesh, Paquistão etc.) a produção e comercialização de etanol e biodiesel, embora incipiente, vem se destacando pelo seu dinamismo e rápida expansão.

\section{Conclusão}

Por motivos ambientais e tecnológicos o Brasil é apontado, na maioria dos estudos, como o país que lidera o setor de bioenergia. Em países tão diferentes como Argentina, Colômbia e Peru os governos estão procurando instituir forte infra-estrutura regulatória para servir de base para essa nova indústria sendo na maior parte dos casos adaptações da experiência brasileira. A participação do setor privado é heterogênea, sendo a Argentina e a Colômbia os países que recebem dele o maior número de investimentos. A cooperação entre Argentina e Brasil ocorre principalmente por meio de negociações no âmbito do Mercosul e entre o Brasil e o maior país latino-americano produtor de petróleo é conduzida por meio de suas grandes empresas exploradoras de recursos fósseis, a PDVSA e a Petrobras.

O Brasil possui diversas parcerias na área dos biocombustíveis com a maioria dos países da América Latina. O Chile e o Equador não formalizaram um relacionamento com o Brasil, mas já existem negociações informais para que isso ocorra. Com o Peru o país tem um programa de pesquisa cooperativo na área de biotecnologia e biocombustíveis. Recentemente os dois países assinaram um acordo para desenvolver conjuntamente insumos alternativos para biocombustíveis. As companhias estatais de petróleo do Brasil e da Colômbia têm um acordo técnico de cooperação e formam uma espécie de joint venture onde os negócios

25 http://www.palmoil.com/ Disponibilidade em 13/06/2007

26 APANADA, Marlon Joseph S. Using Policy Tools to Maximize Biofuels Opportunities. Government and Private Sector Partnership in Biofuels: The Philippine Experience. Editor, www.bioethanol.com.ph. http://www.bioethanol.com.ph/info_database/Maximizing\%20Policy\%20Tools\%20for\%20Biofuels\%20 Opportunities.pdf 
predominantes são os relacionados aos biocombustíveis. Praticamente todas as empresas latino-americanas envolvidas com a exploração dos combustíveis fósseis estão se envolvendo com a produção e comercialização de biocombustíveis.

Em março de 2007, quando da visita do presidente George Bush ao Brasil, foi assinado um memorando de cooperação na área dos biocombustíveis. Brasil e Estados Unidos são responsáveis por $70 \%$ da produção mundial desse combustível e este fato tem sido constantemente evidenciado. $\mathrm{O}$ acordo expressa a intenção dos dois países cooperarem no desenvolvimento e difusão dos biocombustíveis numa estratégia de três níveis (bilateral, com terceiros países e global).

Paralelamente a assinatura do memorando, Brasil, África do Sul, China, Estados Unidos, Índia e a União Européia anunciaram a criação do Fórum Internacional de Biocombustíveis na sede da Organização das Nações Unidas (ONU). O principal objetivo do fórum é discutir o aumento da eficiência na produção, na distribuição e no consumo dos biocombustíveis em escala mundial; preservando o meio ambiente e a produção de alimentos. Os interesses de grandes produtores e ao mesmo tempo grandes consumidores de biocombustíveis estão representados nesse fórum que poderá impulsionar o desenvolvimento de um mercado global dessa fonte energética renovável.

Esse mercado pode ser impulsionado com a especialização latino-americana de produção de etanol e biocombustível e sua exportação para os países asiáticos com restriçóes de terra e tecnologias para o seu desenvolvimento. Além das restrições de áreas agricultáveis a maior parte dos países asiáticos apresenta grande densidade demográfica e à insegurança alimentar pode-se se somar à segurança energética. Os acordos de cooperação entre esses países e os latino-americanos, principalmente os produtores dos mesmos insumos básicos para a produção de etanol ou biodiesel devem ser estimulados. Índia e Brasil, por exemplo, são os dois maiores produtores mundiais de cana-de-açúcar e desde 2003 possuem um memorando para cooperação no desenvolvimento tecnológico do uso de etanol como combustível.

Entre esses dois paises existem também variadas joint ventures como a da Dedini e o Grupo Uttan e a da Petrobras e a Oil and Natural Gás Corporation (ONGC). A Petrobras também possui uma joint venture com a Nippon Alcohol Hanbai que comercializará etanol brasileiro no Japão a partir de 2008. O ministério da agricultura brasileiro desde 2005 possui um acordo de cooperação com o Japan Bank for International Cooperation (JBIC) e um grupo de trabalho sobre biomassa vem discutindo oportunidades de maior cooperação bilateral. Com a Tailândia existe um memorando para troca de informações e exportação de etanol brasileiro para aquele país. Esses acordos devem ser incentivados e ampliados para que a indústria dos biocombustíveis ganhe escala global de produção e comercialização.

Como em qualquer indústria em expansão é crescente o número de entusiastas por mudanças e de críticos conservadores ou proponentes de alternativas. Entre 
os entusiastas encontram-se praticamente todos os relatórios governamentais e de bancos de investimentos internacionais ou locais. $\mathrm{O}$ relatório do Banco Interamericano de Desenvolvimento mencionado anteriormente, por exemplo, diz que o desenvolvimento dos biocombustíveis é benéfico para os países, pois ao se estimular uma indústria tecnologicamente avançada se melhorará a renda e a qualidade de vida de populações que vivem nas zonas rurais. Além disso, enfatiza a redução à vulnerabilidade energética de pequenas economias que são na sua totalidade dependentes da importação de petróleo.

Os críticos, por sua vez, enfatizam questôes ambientais, de segurança alimentar e exploração do trabalho em extensas produções de monoculturas. Eles chamam a atenção para o desmatamento e exploração irracional dos solos e a pouca contribuição dos biocombustíveis para a diversificação das matrizes energéticas dos diferentes países ou mesmo sua contribuição para a redução de gás carbônico na atmosfera. Eles apontam com freqüência o aumento dos preços dos produtos agrícolas que não mais serão produzidos para o consumo humano e animal e direcionados para a produção de combustível. Como alternativas muitos apontam para uma maior racionalização dos atuais recursos energéticos, maiores investimentos no desenvolvimento da energia eólica, nas pesquisas que buscam a utilização do nitrogênio como combustível etc.

Para aproveitar o potencial real da bioenergia é necessária uma mudança importante nas expectativas e nas políticas atuais. Deve ser dada uma maior prioridade à pesquisa, não somente de tecnologias, mas também do custo e disponibilidade dos insumos. Maior esforço necessita ser dispendido para avaliar a importância dos biocombustíveis enquanto mais uma commodity comercializada internacionalmente para o aumento do emprego, da renda e do desenvolvimento dos países. Sem os subsídios, os biocombustíveis não podem competir com o petróleo e seus derivados na maioria dos países. Além disso, a quantidade de terra cultivável requerida para a produção dos mesmos é um recurso limitado na maioria dos países e pode prejudicar o fornecimento de alimentos ou mesmo de água que vem se tornando um recurso escasso em várias regiões do planeta.

Recebido em 1 de outubro de 2007 Aprovado em 25 de fevereiro de 2008

\section{Abstract}

This paper presents Latin American and Asian perspectives on the biofuels emerging industry. The Brazilian's possibilities of participation on this industry evolution and the involvement on the world trade for ethanol and biodiesel are discussed. Also, an investigation about who will be the main "strategic" partners of Brazil in this sector is made: the huge consumer markets of developed countries or the emerging and also hungry consumers of energy Asian economies? 


\section{Resumo}

Este trabalho apresenta as perspectivas latino-americanas e asiáticas na emergente indústria dos biocombustiveis. As possibilidades brasileiras de participação na indústria e no comércio internacional de etanol e de biodiesel são discutidas. Uma questão sobre os possíveis parceiros "estratégicos" do Brasil neste setor é levantada: os enormes mercados consumidores de países desenvolvidos ou os emergentes e também famintos consumidores asiáticos de energia?

Palavras-Chave: Biocombustíveis, América Latina, Ásia Key words: Biofuels, Asia, Latin America 